\title{
Research on the Construction Path of Ideological and Political Edu- cation for Postgraduates in the Era of Artificial Intelligence
}

\section{Ting Liu Anping Wang*}

School of Marxism, Anhui University of Technology, Maanshan, Anhui, 243032, China

\section{ARTICLE INFO}

Article history

Received: 9 December 2020

Revised: 16 December 2020

Accepted: 9 April 2021

Published Online: 16 April 2021

Keywords:

Artificial intelligence era

Graduate students

Ideological and political education

Path

\begin{abstract}
Postgraduate ideological and political education is an important part of ideological and political education in colleges and universities. It is the core of implementing the party's educational policy, comprehensively improving the quality of education, and building a modern socialist education power. In the era of artificial intelligence, innovate classroom education of ideological and political education for graduate students through intelligent network systems, natural language understanding systems, and knowledge processing systems; use intelligent search systems, symbol processing systems, and combined planning systems to deepen the communication links of graduate ideological and political education; through enhancing digital intelligence tools such as genetic algorithm, deep learning algorithm and artificial neural network algorithm to reconstruct the evaluation criteria of graduate ideological and political education is an important engine to promote the intelligent, contemporary and diversified development of graduate ideological and political education in my country.
\end{abstract}

\section{Introduction}

On July 29, 2020, General Secretary Xi Jinping pointed out: "Graduate education plays an important role in cultivating innovative talents, improving innovation capabilities, serving economic and social development, and promoting the modernization of the national governance system and governance capabilities". ${ }^{[1]}$ Postgraduate ideological and political education is an important part of improving the country's centripetal force, national cohesion and the party's ruling power. The profound changes in productivity, production methods, and production relations brought about by the era of artificial intelligence will inevitably lead to profound changes in the construction of postgraduate ideological and political education in my country. General Secretary Xi Jinping emphasized:

*Corresponding Author:

Wang Anping,

female, from Shucheng, Anhui, associate professor at the School of Marxism, Anhui University of Technology, PhD student at the School of Marxism, Nanjing University of Aeronautics and Astronautics.

E-mail:836022637@qq.com.

About the first author:

Ting Liu,

female, from Dengzhou, Henan, a postgraduate of the School of Marxism, Anhui University of Technology.

Fund Projects:

2020 Ministry of Education Humanities and Social Science Research Planning Fund Project: Research on the History of the Communist Party of China's Ideological Work in the 70 Years since the Founding of New China (20YJA710035); Humanities and Social Science Research Key Project of Anhui Province Colleges and Universities (SK2017A0066). 
"Actively promote the deep integration of artificial intelligence and education, promote educational reform and innovation, and give full play to the advantages of artificial intelligence." ${ }^{,[2]}$ Comprehensively strengthen ideological and political work in schools at all levels and types, and promote comprehensive reforms in the education field.$^{[3]}$ Seizing the opportunity of the artificial intelligence era and innovating the construction path of ideological and political education for graduate students in my country is an inevitable requirement for promoting the modernization of education in my country to achieve leapfrog development, breakthrough improvement and continuous progress.

\section{Smart Carrier Innovates Classroom Edu- cation of Ideological and Political Education for Graduate Students}

In the era of artificial intelligence, with the support of intelligent carriers, the classroom education of ideological and political education for postgraduates in colleges and universities will be transformed in the direction of more precision, virtualization, systematization and standardization. The integration of postgraduate teachers and intelligent carriers makes the educating role of teachers, the role of artificial intelligence knowledge transfer, and the role of students as the main body of learning more prominent. We will usher in a profound transformation of postgraduate ideological and political classroom education. Xi Jinping pointed out: "We must attach great importance to the ideological and political work of the young generation, improve the ideological and political work system, and continuously innovate the content and form of ideological and political work." ${ }^{[4]}$ Through the intelligent network education system, natural language understanding system, knowledge processing system, etc., Postgraduate teachers and artificial intelligence will give full play to their respective advantages to provide a good classroom education atmosphere for ideological and political education.

First, the intelligent network education system improves the flexibility of postgraduate ideological and political classroom education. Under the traditional classroom education model, a three-foot podium, student desks, a flat blackboard, and a few pieces of chalk are all equipment for the ideological and political teachers. Engels pointed out: "Our party has a great advantage, that is, it has a new scientific point of view as the theoretical basis." ${ }^{[5]}$ In the era of artificial intelligence, the specific environment, personalities, and hobbies of graduate students are also each is different, and the demand for ideological and political education also presents multi-level, diversified, and multi-faceted characteristics. It is necessary to organically combine classroom teaching and practical teaching. ${ }^{[6]}$ With the development of intelligent network systems, distance education, online education, and online education have become more and more widespread. The intelligent network system is able to collect, record and systematically analyze the learning situation of graduate students. On the basis of in-depth understanding of the personality characteristics of graduate students, it can establish a postgraduate education field integrating online and offline integration and interaction inside and outside the classroom. The provision of authoritative and immediate educational content has increased the selectivity and adaptability of educational content in ideological and political classrooms for graduate students.

Second, the natural language understanding system deepens the teacher-student interaction in graduate ideological and political classroom education. Restricted by traditional objective conditions, most of the interactive exchanges between graduate students and teachers can only stay at a shallow level, short-term, light-contact and general exchanges. With the advent of the era of artificial intelligence, the ideological and political classroom education of graduate students has begun to undergo substantial adjustments. An environment that conforms to the main scenario allows teachers and students to interact in multiple directions across time and space. Natural language understanding system is an important carrier for two-way and even multi-directional interaction between graduate students and teachers. It can take graduate students as the center and use artificial intelligence technology to capture the thought dynamics of graduate students at any time. Through the in-depth interaction between teachers and students, teachers can obtain more information about graduate students' thoughts, innovate methods of ideological and political education, and improve graduate students' ideological and political education. Pertinence, timeliness and science.

Third, the knowledge processing system can accurately feedback the knowledge of postgraduate ideological and political classroom education. Ideological and political teachers should not only give students some abstract concepts, but should observe and understand the positions, viewpoints, and methods of the contemporary world and contemporary China ${ }^{[7]}$. In the era of artificial intelligence, with the development of smart technologies such as short videos, self-media, and smart platforms, postgraduate ideological and political data are constantly enriched and developed. The knowledge processing system even understands graduate students better than graduate students themselves. The development of the knowledge process- 
ing system will break through the limitations of traditional ideological and political classroom education, and better meet the needs of graduate ideological and political classroom education through automatic correction, intelligent problem solving, online tutoring, and instant feedback. Artificial intelligence based on big data, blockchain, and the Internet of Things has richer knowledge reserves, more systematic inductive analysis and logical thinking capabilities than humans, and can well improve the accuracy of postgraduate ideological and political education knowledge feedback. With the further development of artificial intelligence, the knowledge processing system will become an intelligent tutor, career planner and guiding analyst for graduate ideological and political classroom education.

\section{High-Tech Deepen the Extracurricular Strengthening Link of Ideological and Politi- cal Education for Graduate Students}

This thought process that takes place in people's minds is ultimately determined by people's material living conditions. ${ }^{[8]} \mathrm{Xi}$ Jinping emphasized: "We must pay attention to strengthening ideological and political education in schools, and put the spirit of patriotism throughout the entire process of school education at all levels and types." ${ }^{\text {"[9] }}$ The ideological and political education of graduate students in the era of artificial intelligence is a complex, linked, and interactive process. Systematic engineering. The dissemination link of ideological and political education for graduate students in the era of artificial intelligence cannot follow the traditional simplification, simplification, and superficial line. It is necessary to deepen the reform of ideological and political education for graduate students in our country from the height of training qualified socialist builders and successors, in order to realize the Chinese nation the great revival of the Chinese Dream provides talent support.

First, the intelligent search system improves the ability to accurately push postgraduate ideological and political education. A person is a person in the process of development that is realistic, can be observed through experience, and under certain conditions. ${ }^{[10]}$ In the traditional state, the extracurricular ideological and political education work of graduate students is mainly done by the counselor. The time and energy that the counselor spends on each graduate student is very limited, and they cannot accurately grasp the ideological status of each student and teach in accordance with their aptitude. , Greatly reducing the influence, appeal and dissemination of postgraduate ideological and political education. In the era of artificial intelligence, the intelligent search system can conduct indepth analysis and excavation of students' recent learning, ideological and political conditions through multiple perspectives, multiple indicators, and multiple levels through speech recognition, language processing, and emotional analysis. Reliable helper. The intelligent search system can comprehensively process massive amounts of relevant information about postgraduate ideological and political education, efficiently analyze students' situations to generate decision-making information, and promote the smooth development of postgraduate ideological and political education.

Second, the symbol processing system deepens the spreading influence of postgraduate ideological and political education. In the era of artificial intelligence, the dissemination of postgraduate ideological and political education will undergo structural changes. The ideological and political education of graduate students has moved from in-class to extra-curricular, from inculcation to interactive entertainment, and more attention is paid to the subtle influence of ideological and political education on graduate students. The integration of ideological and political education into all aspects of postgraduate teaching has become a political responsibility, life attitude and thinking habit of postgraduates. In the era of artificial intelligence, the development of symbolic processing systems will change the organization of traditional teaching, allowing graduate ideological and political education to break through the limitations of time and space, groups and organizations, and realize ubiquitous and all-time "ubiquitous learning". The artificial intelligence symbol processing system can be based on the needs of graduate students, so that students can obtain the massive information they need from smart devices, thereby improving the theoretical knowledge, teaching skills and ideological practice of graduate ideological and political education. It also puts forward requirements for the policy of sending newspapers by young Hegel.

Third, the combined planning system promotes the participation of multiple subjects in postgraduate ideological and political education. The traditional model of postgraduate ideological and political education is a tree-like relationship. The Ministry of Education sets the teaching goals of postgraduate ideological and political education in colleges and universities, and universities allocate the curriculum planning of postgraduate ideological and political education to graduate teachers. Channels conduct ideological education to students. The tree-like model of postgraduate ideological and political education cannot adapt well to the diversified, intelligent, and individualized education paradigm in the intelligent era, and it is 
easy to promote the negative influence of indoctrination, scrambling, and compulsory traditional education. In the era of artificial intelligence, the development of the combined planning system enables students' individualized, diversified, and differentiated needs to be met to the greatest extent. Through dialogue with the government, corporate docking, social convection, etc., it creates greater development space for graduate ideological and political education. Development Opportunities.

\section{Digital Intelligence Tools to Improve the Evaluation Criteria of Postgraduate Ideologi- cal and Political Education}

Assessment is an important part of postgraduate ideological and political education, which determines the logical generation, trend and development quality of postgraduate ideological and political education. The assessment and evaluation of postgraduate ideological and political education in the era of artificial intelligence will change the traditional static, fuzzy, and single evaluation standards, and turn to dynamic, precise, and diversified evaluation standards. It will be checked by genetic algorithms, deep learning algorithms, and artificial neural network algorithms. Data analysis and precise judgments of classroom interaction, practical exploration and value thinking of graduate students' ideological and political education will maximize the scientificity, rationality and accuracy of the evaluation of graduate students' ideological and political education.

First, genetic algorithms deepen the classroom evaluation of postgraduate ideological and political education. In the era of artificial intelligence, with the in-depth development of genetic algorithms, the evaluation of postgraduate ideological and political education will shift from personal subjective evaluation to subjective and objective bidirectional evaluation centered on big statistics, big data, and big algorithms to improve the accuracy of postgraduate ideological and political education, Scientific and effective. Genetic algorithms can use massive data admission and storage to develop visual, three-dimensional, and systematic chart analysis of students' classroom speeches, teacher-student interactions, homework completion, etc., to help teachers conduct targeted education and improve graduate students the efficiency of ideological and political education. In the era of artificial intelligence, it is necessary to give full play to the role of genetic algorithms as an "accelerator" for the reform of postgraduate ideological and political education, evaluate the strengths, potentials and shortcomings of postgraduates through intelligent technology, propose personalized learning programs, and train qualified socialist successors.

Second, deep learning algorithms improve the practical evaluation of graduate ideological and political education. Deep learning algorithms can timely capture students' data on intelligent platforms such as learning platforms, educational administration systems, media interactions, etc. in online ideological and political theory education, daily ideological and political education, and propaganda and ideological education, and obtain educated and educated online Explicit data such as facial expressions, gestures, and speech expressions during the interaction. Indepth analysis of the degree of knowledge, concentration, and participation in the ideological and political education of postgraduates is carried out, and the dynamic image of postgraduate ideological and political education is drawn more comprehensively, which provides data support for improving the quality of postgraduate ideological and political education. Teachers are the leader in the process of postgraduate ideological and political education. Teachers should actively participate in the practical evaluation of postgraduate ideological and political education, and use their own practical experience, professional knowledge and educational ability to improve the application of deep learning algorithms in postgraduate ideological and political education Sexuality, scientificity and accuracy.

Third, the artificial neural network algorithm multi-dimensional analysis of graduate students' thinking dynamics. "People are the prerequisite and core element of ideological and political education. Ideological and political education is, in the final analysis, the work of being a person, and it is the work of people's ideology." ${ }^{,[11]}$ Under the traditional evaluation model, the employment rate, entrepreneurial rate and enrollment rate are measured Important standards for the effectiveness of graduate education have played an important role in improving the quality of graduate education in the past. The goal of education is to train well-rounded talents. In the era of artificial intelligence, the development of artificial neural network algorithms can conduct multi-dimensional analysis and comprehensive feedback on the ideas, ideals, beliefs, and practical behaviors of graduate students, and more comprehensively and objectively evaluate the effectiveness of graduate ideological and political education. The artificial neural network algorithm is used to break the traditional evaluation orientation of "efficiency first," and dynamic data analysis is used to improve the foresight, pertinence and effectiveness of postgraduate ideological and political education.

Young people are the future of the motherland, the hope of the nation, and the future and hope of our party. ${ }^{[12]}$ Postgraduate ideological and political education is 
a systematic project of great strategic significance. Deepening the integration of artificial intelligence technology and postgraduate ideological and political education is an inevitable requirement for accelerating the construction of a strong country in learning, education, and culture. Xi Jinping emphasized: "Ideological and political theory courses should insist on strengthening in improvement, improving in innovation, timely update of teaching content, enrich teaching methods, and continuously improve classroom teaching conditions to prevent formalization, superficiality, etc. ${ }^{\left[{ }^{[13]}\right.}$ In the era of artificial intelligence, postgraduate ideological and political education must adhere to the integration and unity of individualization, innovation and life-oriented, and use artificial intelligence technology to exceed the limitations of individual cognitive abilities from the perspective of positioning height, theoretical depth and practical dimensions. Based on big data intelligent analysis, natural language symbol interaction as the core and intelligent platform as the carrier, according to the cognitive structure, ability characteristics and knowledge needs of graduate students, propose strategies, methods and paths suitable for current graduate ideological and political education to promote graduate students' thinking Political education starts a new journey, enters a new stage, and achieves new development. Artificial intelligence technology has brought about a huge change in the construction path of postgraduate ideological and political education. Realizing the deep integration of artificial intelligence technology and postgraduate ideological and political education requires the joint efforts of all members of the society.

\section{References}

[1] Wang Xingwei. The "Four Transformations" of Graduate Cultivation under the Integration of Science and Education [N]. China Education News, 2020-11$23(5)$

[2] Tao Xiping. Actively promote the deep integration of artificial intelligence and education [N]. China Education News 2019-06-15 (3).

[3] Xi Jinping's speech at the symposium of representatives of experts in the fields of education, culture, health and sports [N]. People's Daily, 2020-09-23 (002).

[4] Zhou Yuepeng. Youth ideological and political work must keep up with the development wave of the omnimedia era [EB/0L]. (2019-01-31) [2020-1101]. http://www.qstheory.cn/laigao/ ycjx/2019-01/31/ c $1124071391 . \mathrm{htm}$

[5] Selected Works of Marx and Engels: Volume 2 [M]. Beijing: People's Publishing Hous, 1995.

[6] Huang Zigen. To better integrate Chinese excellent traditional culture into the construction of ideological and political courses [N]. Economic Daily, 2020-1028 (11).

[7] Zhao Min. Ideological and political courses should focus on value shaping [N]. People's Daily, 2020-0119 (05).

[8] Selected Works of Marx and Engels: Volume 4 [M]. Beijing: People's Publishing House, 1995.

[9] Today, how are we patriotic? Hear what General Secretary Xi Jinping said [EB/OL]. (2020-10-08) [202011-01] http://www.people.com.cn/n1/2020/1008/ c164113-31884193.html.

[10] Collected Works of Marx and Engels: Volume 1 [M]. Beijing: People's Publishing House, 2009:525.

[11] Sun Qiang. Frontier Research of Ideological and Political Education[M]. Beijing: People's Publishing House, 2013:148.

[12] Book writing group. Speech at the celebration of the 90th anniversary of the founding of the Communist Party of China $[\mathrm{M}]$. Beijing:People's Publishing House, 2011.

[13] Liu Jianjun. A close experience of General Secretary Xi Jinping's cordial care [J]. Journal of Ideological and Theoretical Education, 2019(04): 11. 